\title{
Process Management for e-Learning Quality
}

\author{
Rogério Rossi and Pollyana Notargiacomo Mustaro
}

\begin{abstract}
Well-defined process can support product development and implementation of services in several sectors as industry, commerce and service areas. For the development of educational products or for the implementation of educational services, processes management also has relevance. To be institutionalized they require proper and specific mechanisms and to be implemented they could follow a methodological approach as it is presented in this article. Specific frameworks to education area are presented and they can support the implementation of such processes which favors considerably the quality of products and services. Some of these frameworks are highlighted and an analysis presents its relation to six dimensions of quality for education products and services. An in-depth treatment about quality related to the processes demonstrates the importance of process management with a view to their continuous improvement to meet the quality requirements.
\end{abstract}

Index Terms-Process, process management, educational products and services, quality in education.

\section{INTRODUCTION}

The importance related to the process management is considered in many areas of modern society. Industry, commerce and service areas are examples that consider the process management as an important tool to develop, deliver and maintain their results. For the education area, this type of management is being increasingly sought, especially when it comes to consider the implementation of programs and courses offered with the support of Information and Communication Technologies (ICT). The education area can consider products and services supported by digital technologies as distance education, e-learning or learning objects that require several elements to be implemented, such as, instructional design, theories of pedagogy and psychology, computing and heavy application of management concepts, including an enhanced vision of process management.

To [1] the process management is an essential approach in all areas of the economy, including education and it is clear that classical frameworks are not applicable to education in an immediate view. Thus there is a clear necessity to establish specific frameworks for process management in the educational area.

Developers, buyers and users of these products and services are increasingly aware of its quality, so these frameworks can enable significant improvements in the quality of educational products and services. To [2] "quality development in e-learning becomes more and more important A lot of approaches have been developed to improve educational processes in this field".

This reality can be seen by the actions of governments and regulatory institutions or associations that seek to create models and standards to promote the capacity of educational products development with better quality, as well as execute and deliver better services. The growing number of frameworks for this purpose can also be observed and some of these are presented in more detail in later section of this article. For [3] quality in the field of e-learning is an issue of relevant importance.

References [4], [5] present relevant research studies that demonstrate the existence of these types of frameworks to support quality in education area supported by ICT. References [6]-[8] also present results in this direction that can sustain the quality processes in this area.

Often these frameworks are supported by governments or organizations seeking to make them an international standard for the industry, but there are also process models from academic proposals that have equal importance and relevance promoting the quality of education. [9] creates an evolutionary approach for developing e-learning product named 'Evolutionary Development Process Model to e-learning' that specifically considers two groups of processes: 1) Process and Project Management 2) Process Product Development. Reference [10] consider a set of processes for e-Learning product which is termed as the 'Life-Cycle of the e-Learning Process', is a life cycle that includes four phases, namely: 1 - Learning design; 2 Learning Production; 3 - Learning Deployment; and 4 Learning Assessment. [11] proposes a model for the development of learning objects where there are processes that consider instructional design and it is called 'Instructional Design Process' which details the formal steps for the development of learning objects. These are examples of process management practices applied in education area.

To deepen these introductory notions about the quality relationship in the education area with established processes and possible frameworks that can be adopted in order to improve the quality requirements of educational products and services, the following sections are described in this article: the second section presents an approach of processes and concepts related to process management and its application; the third one presents the processes management in education; the fourth section presents the frameworks that support the design processes for educational products and services, such as e-learning or distance education; and, finally, on the fifth section are presented the conclusions and suggestions for future research related to this area of study.

\section{PROCESS: DEFINITION AND APPLICATION}

The current achievements, whether these are products 
developed or services performed, are demanding increasingly precision and accuracy in order to meet an ever more demanding consumer in any of the areas as industry, commerce, entertainment, tourism, financial market, education, etc. The results provided whether a manufactured product or a service such as "delivery" is questioned by their consumers when they displease them. Their questions revolve around the activities seeking to understand why services are sometimes not satisfactory and products sometimes have so many defects. Thus seek to find defects in the activities and times, as customers, proposes enhancements that could be applied. These activities are part of the production processes, either the product or service made available.

The processes can be considered simple by a dissatisfied customer, but complex by a manager or a professional of a particular area. Actions and investments are required to mapping the process to define and publish them until they can be continuously improved.

The processes reflect the activities and techniques employed for the definition, design, construction and maintenance of a product and represent the activities that can allow for a service. They include the set of activities used to meet a certain goal. To [12] "a process can be defined as the logical organization of people, materials, energy, equipment, and procedures into work activities designed to produce a specified result" and for [13] "process is a sequence of steps performed for a given purpose; for example, the software development process".

Process management is currently used extensively in contemporary society and it is considered in many areas to promote the management of human activities on the achievement of products and services. They have relevants properties to the type of measurement that occur, especially when these processes are formalized and well understood by trained professionals, favoring the approaches related to quality. To [14], the structuring of processes provides conditions to manage risk reduce management and increase uncertainty (manageability).

In fact the processes are formal components and integrators in many types of organizations. They define the logical order in the production area and should not hindering the activity within the environments but facilitate it. Although sometimes, when these processes become very formal, in some cases, it can create some difficulties in people action instead of facilitate. This may occur because of the way that these processes are defined and institutionalized. Processes should be seen as a beneficial element, they are intrinsic to people's daily actions in the organization and its formalization should encourage those involved when it occurs in a structured and integrated manner.

Organizations from different areas, as previously mentioned, are founded on this concept and get out with their adoption, i.e., the processes are capable of supporting the activities performed on the industry's production line, the commercial management of a network of shops, the administrative and technical activities of a hospital, in the software industry and the daily achievements of the educational institutions.
In general, in a simplified view, the processes comprise a series of grouped activities prescribing actions for people to perform them. The processes within the organization are sometimes formal but it may be used informally, leaving that each of the stakeholders using it in your mode. The informal characterization eliminates the benefits this could bring to the organization. The formalization of the process establishes some other indirect and direct benefits to the organization that believes on it.

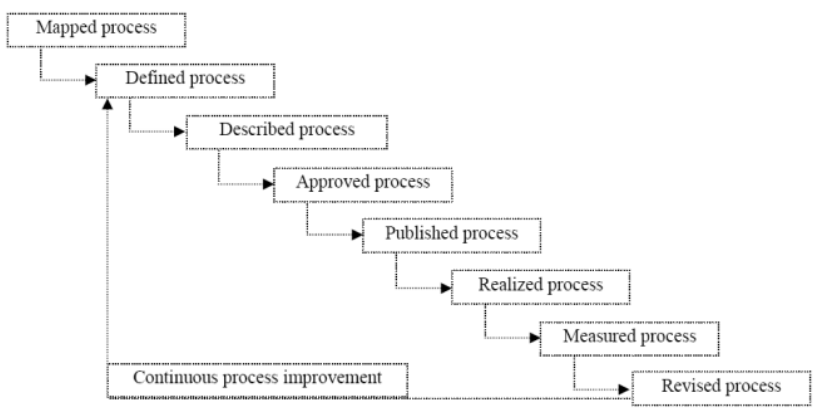

Fig. 1. Methodological approach for process management.

The formalization of an organizational process can follow a certain cycle of implementation and maintenance, and once implemented, the existing integrated with other processes, may allow for greater efficiency in what is called process-based management.

In a macro view [15] proposes a process for software product development with three phases: 1 - Definition which focuses on 'what'; 2 - Development - which focuses on 'how' and finally; 3 - Maintenance - which holds the 'changes' pertaining to any product or service. It represents a general approach that can be applied to any category of product or service to be built in a formal process model, requiring adjustments accordingly the specificity of the product or service.

Reference [16] proposes an infrastructure to support effective process performance that should provide roles and mechanisms that will lead to the process displaying the following characteristics: defined, owned, trained, supported, followed, monitored, and continuously improved.

For the process implementation, a methodology is proposed in order to promote its formalization of implementation. [17] suggests that the improvement process has five basic elements: 1) an correct understanding of the current status of the process; 2) the vision of the desired process; 3) a prioritized list of actions required for improvement; 4) a plan to accomplish these actions; and 5) the resources and commitment to execute the plan. For these actions are met often establishes the implementation of procedures based on some recognized standard framework on a large scale, but this is not a requirement being that the processes can be defined and implemented independent of it An approach to implementing process is shown in Fig. 1.

The cycle of process prescribes a series of phases in a methodological view that allows the use of this process by means of measuring mechanisms suffer continuous improvements that can provide a more favorable degree of the expected results with performance the established process. 


\section{Process Applied to Education Management}

Processes are applied in many areas of society and can also be broadly applied in education, a significant area that needs many types of products and services, especially ICT based. In this sense, the demands for quality are more stressed and therefore the formalism for the definition, development and maintenance of such products and services with higher quality demands greater professional effort.

One element that contributes greatly to these actions is related to instructional design theory as it relates to a structured form of activities and techniques for process-oriented product development and delivery of services, although these concepts are not applied in all institutions.

According to [18] in most conventional higher education institutions, the process of course development is carried out alone and without specific queries. The same authors state that the emergency delivery of online courses is contributing to change these processes to develop these courses.

It is possible to verify that a lot of process models used in large-scale or developed solely for an institution contributes to the definition, development and maintenance of educational products and services that are supported by ICT.

Some researches point to the need for a specific and unique standard to these products, which is being sought from studies and proposals related to these educational products. These standards are being created from assessments and verifications of developing these types of products. To [9] the conventional system development process models and development approaches are too general and they are not adequate to be applied to e-Learning as they are.

It can be considered that an effective process management in the education for products ICT based can specifically consider six quality dimensions: 1) didactic-pedagogical dimension; 2) technologic dimension; 3) management dimension; 4) tutorial dimension; 5) support dimension; and 6) evaluation dimension, as evidenced in Fig. 2. Each of these considers a set of specific activities that must be implemented in an integrated manner for effective process management of educational products ICT-based.

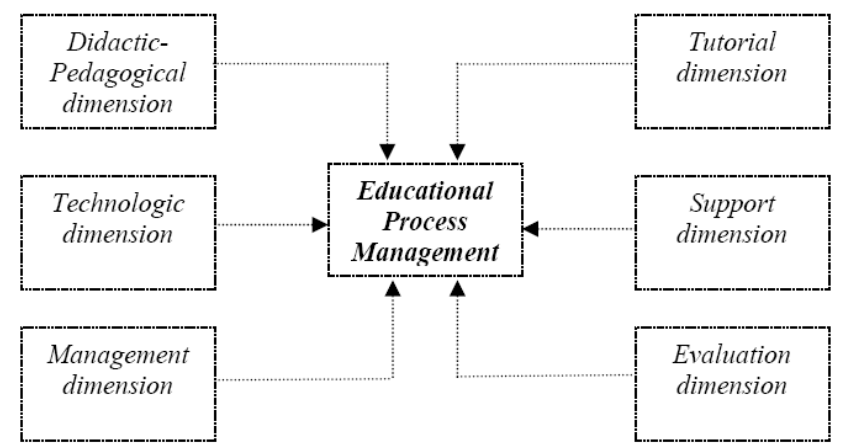

Fig. 2. Quality dimensions for educational process management.

The Didactic-Pedagogical Dimension considers the theories arising from this particular branch, and culminates in an emphatic manner in the principles of instructional design that effectively supports the construction of courses and their subsequent maintenance. In general, this theory supports the integration of the pedagogical processes to the others processes used to manage the educational institution in the sense that contribute to the elements related to the objectives of instruction, performance, strategy and evaluation. It can be seen in a systematic approach according to [19] to instructional design that supports this dimension. To [20] "one of the most crucial prerequisites for successful implementation of e-Learning is the need for careful consideration of the underlying pedagogy, or how learning takes place online".

The Technologic Dimension should cover and support the entire technological apparatus necessary to support an educational product or service. Many technological components are considered in this dimension: software, hardware, elements of communication, databases, etc. The processes of this dimension must meet the approaches of acquisition or development of these components (specifically the software product) and their integration into the educational system. The software product can be developed internally by the educational institution and thus, this type of development requires mature processes for the production of software quality that can be integrate to the system and produce effective results.

The Management Dimension should consider all management actions related to the development, deployment and maintenance of products and services supported by ICTs. For example, the necessity to implement a set of online courses, or produce or acquire an e-learning product or a group of learning objects. All this actions must follow a defined and standardized procedure so that your creations or acquisitions and subsequent integration to the educational system occur in a professional and effective manner.

The Tutorial Dimension should consider all the actions involved in tutoring, which requires preparations for the realization of the tutorials by the tutors, considering both the educational strategies and preparation for the use of technologies involved and the monitoring of the performance thereof.

The Support Dimension must consider all actions aimed at supporting the learner, involving items such as infrastructure and online telephone service, providing tutorials so they can learn to manipulate the tools necessary to carry out the courses, among others.

The Evaluation Dimension should consider all management actions relevant to the development to structure the diagnostic assessments (for analysis of student profile), the type of assessments: summative and formative, and self-assessments to favor self-regulated learning.

These dimensions of quality for educational processes is closely related to processes to be implemented by an educational institution and in turn, such processes can be better enabled to follow any model or some kind of standard that can facilitate the implementation of them. A relationship between the dimensions of quality and processes can be identified in the next section.

\section{FRAMEWORKS FOR E-LEARNING AND ONLINE COURSES}

The processes are crucial, and exist, either formally or informally, to manage all activities governing the educational management. Special attention is given in this section to the educational management of the products and services that are 
supported by Information and Communication Technologies (ICT). These products and services require high levels of quality, either by the producers (those who develop and offer products, for example, e-learning), whether on the part of buyers (institutions that use these products and offer their services integrated these) or by the users themselves (students of different levels or even employees in companies doing courses through corporate universities).

The qualitative questions concerning these products and services that elevate the studies conducted in this area in order to propose mechanisms that favor the measurement of quality. However, as seen in the previous section, these mechanisms, in a process view, must meet a set of dimensions that favors the use of these products and good service provision.

However, researches show that many countries (represented by their ministries or departments of education) or public or private entities publishes specific guides, standards and normative for the education area ICT based.

Some frameworks identified in [4]-[6], [21] show the high importance given to the matter and existing contribution, especially by the consideration of the amount of standards documentation that exists in this area.

To [1] "these market oriented quality standards are important for two significant reasons. First, they help purchasers, through criteria and standards, to make appropriate e-learning choices in order to maximize return of investment. Second, they help who develop and offer e-learning".

Reference [6] presents one of the frameworks developed with this intention under the sponsorship of the Canadian government the standard CanREGs (Canadian Recommended E-learning Guidelines). According to [22] it was released in 2002 having been changed to be launched in the global market in 2004 as OeLQs (Open eQuality Learning Standards). It is very important to the review and evaluation of course content, design, for policies, management practices and student support [18].

Other relevant frameworks to be considered are outlined below in order to submit a binding of the process management for the education area that is sustained by digital technologies, they are: 1) IHEP's Quality on the Line: Benchmarks for success in Internet-based Distance Education; 2) the Sloan Consortium Quality Framework and the five pillars; 3) Standards and Guidelines for Quality Assurance in the European Higher Education Area; 4) MEC / SEED Benchmarks for Quality Distance Higher Education; and 5) ISO / IEC 19796-1 Standard on Quality for e-learning. Many others are identified in [23], [24] and widely used by institutions around the world, but these were selected in order link them to the need for a vision of process management and checking the degree of adherence dimensions of quality for the educational process management as shown in Fig. 2.

The IHEP's Quality on the line: Benchmarks for success in Internet-Based Distance Education according to [25] was prepared by The Institute for Higher Education Policy and presents 24 individual quality indicators nominated benchmarks that is considered essential to ensuring excellence in Internet-based Distance Learning. The benchmarks are divided in seven categories of quality measures currently in use: 1) institutional support; 2) course development; 3) teaching and learning; 4) course structure; 5) student support; 6) faculty support; and 7) evaluation and assessment.

The Sloan Consortium Quality Framework and the five pillars is a consortium of institutions and organizations committed to quality online education [26]. Its purpose is to help learning organizations continually improve quality. The framework has five quality principles: 1) Learning effectiveness; 2) Cost effectiveness and institutional commitment; 3) Access; 4) Faculty (employee) satisfaction; and 5) Student (customer) satisfaction. The framework details a set of practices for each pillar.

Standards and Guidelines for Quality Assurance in the European Higher Education Area were published by the European Association for Quality Assurance in Higher Education (ENQA) [27]. The framework presents a set of standards and guidelines for quality assurance in the EHEA (European Higher Education Area). It was developed for the use of higher education institutions and quality assurance agencies working in the EHEA, covering key areas related to quality. It is divided in three parts: 1) European standards and guidelines for internal quality assurance within higher education institutions; 2) European standards and guidelines for the external quality assurance of higher education; and 3) European standards for external quality assurance agencies.

MEC / SEED Benchmarks for Quality of Distance Higher Education, according to [28] is a reference document for quality in distance education. Created in 2003, it has undergone some changes and a new version, in effect, was released in August 2007. The document aims to guide the implementation of programs of distance education since his eight topics are: 1) Design of education and curriculum; 2) Communication system; 3) Didactical material; 4) Evaluation; 5) Multidisciplinary team; 6) Infrastructure support; 7) Academic and administrative management; and 8) Financial sustainability.

ISO/IEC 19796-1 Standard on Quality for e-learning according to [7] and [8] is a framework to describe, compare, analyze, and implement quality management and quality assurance approaches. Part 1 is RFQD (Reference Framework for the Description of Quality) that is divided in seven steps: 1) Needs Analysis; 2) Framework Analysis; 3) Conception/Design; 4) Development/Production; 5) Implementation; 6) Learning Process; and 7) Evaluation/optimization. The ISO/IEC will be developed with three additional parts: Part 2: Quality Model; Part 3: Reference Methods and Metrics; and Part 4: Best practice and Implementation Guide.

The above frameworks are directed to the educational area in the implementation of a robust process management with the aim of quality improvement of educational products as e-learning and distance education. Given the six quality dimensions for educational products and services ICT-based, its relation to the frameworks presented above are showed in Table I. The results showed for each framework considers each dimension. Can be assigned the values 'considered' and 'low considered' for each framework by each dimension after a detailed study realized based on these frameworks. 
TABLE I: RELATIONSHIP OF FRAMEWORS AND QUALITY DIMENSIONS

\begin{tabular}{|c|c|c|c|c|c|c|}
\hline \multirow{2}{*}{ Framework } & \multicolumn{6}{|l|}{ Dimension } \\
\hline & DP & MA & TE & SU & TU & $\mathbf{E V}$ \\
\hline Canadian Recommended E-learning Guidelines & considered & $\begin{array}{l}\text { low } \\
\text { considered }\end{array}$ & considered & considered & considered & $\begin{array}{l}\text { low } \\
\text { considered }\end{array}$ \\
\hline IHEP's Quality on the line & considered & $\begin{array}{l}\text { low } \\
\text { considered }\end{array}$ & $\begin{array}{l}\text { low } \\
\text { considered }\end{array}$ & considered & $\begin{array}{l}\text { low } \\
\text { considered }\end{array}$ & considered \\
\hline Sloan Consortium Quality Framework & considered & $\begin{array}{l}\text { low } \\
\text { considered }\end{array}$ & $\begin{array}{l}\text { low } \\
\text { considered }\end{array}$ & $\begin{array}{l}\text { low } \\
\text { considered }\end{array}$ & $\begin{array}{l}\text { low } \\
\text { considered }\end{array}$ & $\begin{array}{l}\text { low } \\
\text { considered }\end{array}$ \\
\hline $\begin{array}{l}\text { MEC/SEED Benchmarks for Quality of Distance Higher } \\
\text { Education }\end{array}$ & considered & $\begin{array}{l}\text { low } \\
\text { considered }\end{array}$ & $\begin{array}{l}\text { low } \\
\text { considered }\end{array}$ & considered & $\begin{array}{l}\text { low } \\
\text { considered }\end{array}$ & considered \\
\hline ISO/IEC 19796-1 Standard on Quality for e-learning & considered & considered & $\begin{array}{l}\text { low } \\
\text { considered }\end{array}$ & $\begin{array}{l}\text { low } \\
\text { considered }\end{array}$ & $\begin{array}{l}\text { low } \\
\text { considered }\end{array}$ & considered \\
\hline
\end{tabular}

Legend: DP - Didactic-Pedagogical; MA - Management; TE - Technology; SU - Support; TU - Tutorial; EV - Evaluation

The visualization of this relationship between the frameworks with the quality dimensions collaborate to a definition by the educational organizations of them might be used. In a view of process implementation considering an external element, these frameworks are important helpers in this implementation. Especially they lead to improve quality of products and services provided by the institution who adopt them. It can be seen in the next section the link between the institutionalized processes and quality desired by organizations.

\section{CONCLUSIONS AND FUTURE WORKS}

Process management is inherent in many areas belonging to modern society. For the area of education, supported by ICT, culminating in products and services such as e-learning and distance education, structured and formalized activities according to the precepts based on process management can translate into an important mechanism for quality.

Processes should be established and maintained by the organization. In a formal approach should follow a cycle that favors its implementation, mapping, definition, use and practices for continuous improvement. The processes within organizations support the macro-activities such as: design, planning, development and maintenance of products, and the same can be applied to educational products such as e-learning, distance education or learning objects. A set of organization actions promotes activities related to the implementation of processes, such as the strategic definition of quality, cycle for implementing the processes, the definition of resources, etc.

These actions within the educational organization may occur with the use of frameworks, which as shown, can support the institutionalization of processes and meet the quality improvement for educational products. Regardless of the use that is made, a framework can support the activities aimed at the quality of products and services offered.

It is possible to observe a relationship between the characteristics of the frameworks that were cited in this article with a set of quality dimensions, and possibly favor the adoption of the process implementation, aiming at structuring an educational organization.

With a specific measurement program and criteria, the organization' processes should be measured and its improvement should be verified. This kind of measuring of processes can support a cycle of continuous process improvement. Thus it is favor to reach the process maturity and consequently checking quality initially set by the organization.

It is relevant to consider a new research that relates to institutionalization of processes using specific frameworks in order to verify the organization results. Considering other frameworks may also encourage a more detailed studies and investigations on the use of approaches and each can bring about increased understanding of these in relation to desired quality.

\section{REFERENCES}

[1] A. Legait and V. Sandoval, "Quality process: from model to action," Workshop European Quality Observatory (EQO) colocated to the $4^{\text {th }}$ IEEE International Conference on Advanced Learning Technologies, vol. 1, pp. 21-26, August 2004.

[2] U.-D. Ehlers and J. M. Pawlowski, "Learning from experience towards a form model for contextualization of experiences for quality development," Workshop European Quality Observatory (EQO) colocated to the $4^{\text {th }}$ IEEE International Conference on Advanced Learning Technologies, vol. 1, pp. 32-37, August 2004.

[3] A.-M. Husson, "Comparing quality models adequacy to the needs of 'clients' in e-learning," Workshop European Quality Observatory (EQO) colocated to the $4^{\text {th }}$ IEEE International Conference on Advanced Learning Technologies, vol. 1, pp. 4-6, August 2004.

[4] T. Rekkedal. (May 2006). State of the art report on distance learning and e-learning quality for SMEs. E-learning Quality for SMEs: Guidance and Counselings. [Online]. pp. 1-27. Available: http://nettskolen.nki.no/in_english/elq-sme/ELQ-SMEStateofArt.pdf

[5] K. Shelton, "A review of paradigms for evaluating the quality of online education programs," Online Journal of Distance Learning Administration, vol. 10, pp. 1-9, Spring 2011.

[6] K. C. Barker, "E-learnig quality standards for consumer protection and consumer confidence: a Canadian case study in e-learning quality assurance," Education Technology \& Society, vol. 10, pp. 109-119, 2007.

[7] J. M. Pawlowski, "The quality adaptation model: adptation and adoption of the quality standard ISO/IEC 19796-1 for learning, education, and training," Journal of Education Technology \& Society, vol. 10, pp. 3-16, 2007.

[8] F. C. N. Silva, "ISO standards for EAD," in Distance Education: state of the art, M. F. Litto and M. Formiga, Eds., São Paulo, SP: Pearson Prentice Hall, 2009, ch. 6, pp. 35-44.

[9] S. Hadjerrouit. (2007). Applying a System Development Approach to translate educational requirements into e-learning. Interdisciplinary Journal of Knowledge and Learning Objects. [Online]. 3(1). pp. 107-134.

Available: http://www.ijello.org/Volume3/IJKLOv3p107-134Hadj296.pdf

[10] I. Varlamis and I Apostolakis. (2006). The present anf future of standards for e-learning technologies. Interdisciplinary Journal of Knowledge and Learning Object. [Online]. 2(1). pp. 59-76. Available: http://www.ijello.org/Volume2/v2p059-076Varlamis.pdf

[11] P. N. Mustaro and I. F. Silveira. (2006). Learning objects: adaptative retrieval through learning styles. Interdisciplinary Journal of Knowledge and Learning Objects. [Online]. 2(1).pp. 35-46. Available: http://www.ijello.org/Volume2/v2p035-046Mustaro.pdf 
[12] N. S. Godbole, Software Quality Assurance: Principles and Practice, Oxford, UK: Alpha Science International Ltd, 2005, pp. 360-405.

[13] Standard Glossary of Software Engineering Terminology, IEEE Standard STD-601.12-1990.

[14] M. A. Ould, Strategies for Software Engineering: the management of risk and quality, Chichester: John Wiley \& Sons Ltd., 1990, ch. 3, pp. 30-70.

[15] R. S. Pressman, Software Engineering, São Paulo, Brazil: Makron Books, 1995, ch. 1, pp. 3-53.

[16] S. Zahran, Software process improvement: practical guidelines for business success, London, UK: Pearson Education Limited, 1998, ch. 6 , pp. 83-128.

[17] W. S. Humphrey, Characterizing the software process: A maturity framework, Pittsburgh, USA: Addison-Wesley Publishing Company, Inc., 1987, ch. 1, pp. 3-16.

[18] I. T. Chao, T. Saj, and D. Hamilton, "Using collaborative course development to achieve online course quality standards," International Reviews of Reserch in Open and Distance Learning, vol. 11, pp.106-126, October 2010.

[19] W. O. Dick, L. Carey, and J. Carey, The systematic design of instruction, Boston, USA: Allyn \& Bacon Publication, 2005, ch. 1, pp. $1-13$

[20] T. Govindasamy, "Successful implementation of e-leraning pedagogical considerations," The Internet and Higher Education, vol 4, no. 1, pp. 287-299, 2002.

[21] F. M. Litto and M. Formiga, Distance Education: state of the art, São Paulo, Brazil: Pearson Prentice Hall, 2009, ch. 6, pp. 35-44.

[22] K. C. Barker. (January 2002). Canadian recommended e-learning guidelines. FuturEd for Canadian Association for Community Education and Office of Learning Technologies. [Online]. pp. 1-11. Available: http://www.futured.com/pdf/CanREGs\%20Eng.pdf

[23] European Association for Distance Learning (EADL). (2003). Quality Guidelines to improve the quality of distance learning institutes in Europe. [Online]. Available: http://www.eadl.org

[24] D. Keegan, M. F. Paulsenm, and T. Rekkedal. (2002). Megatrens in e-learning provision - literature review Megatrends Project. [Online] pp. 1-47. Available: http://nettskolen.nki.no/in_english/megatrends/

[25] The Institute for Higher Education Policy. (April 2000). Quality on the line: benchmarks for success in internet-bases distance education. [Online]. pp. 1-33. Available: http://www.ihep.org/assets/files/publications/m-r/QualityOnTheLine. pdf

[26] The Sloan Consortium. (2005). The Sloan Consortium Quality Framework and the five pillars. [Online]. pp. 1-9. Available: http://sloanconsortium.org/publications/books/qualityframework.pdf

[27] European Network for Quality Assurance in Higher Education (ENQA). (2005). Standards and Guidelines for Quality Assurance in the European Higher Education Area. [Online]. pp. 5-41. Available: http://www.enqa.net/files/ENQA\%20Bergen\%20Report.pdf

[28] MEC/SEED Ministry of Education and Culture / Department of Distance Education. (August 2007). Quality becnhmarcks for distance education. [Online]. pp. 1-31. Available: http://portal.mec.gov.br/seed/

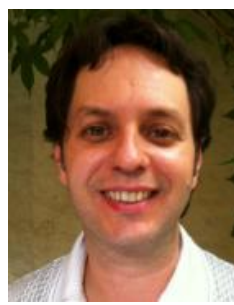

Rogério Rossi was born in São Paulo, on March, 8 1969. He has a bachelor's degree in mathematics by the University Center Foundation Santo André (1991), his Master Degree (1998) is in Electrical Engineering as his Ph.D (2013) both by Mackenzie Presbyterian University that is located in São Paulo, Brazil.

$\mathrm{He}$ is a professor in the Information Technology area and he has experience as a professional for software quality using specific models like CMMi. Currently he is working as a Professor of undergraduate and graduate courses in a university in São Paulo. His publications for the last three years were concentrated in international conferences in his research area. His currently field of study is related to the quality for educational products and services based on digital technologies and his previous research field was concentrated in quality models for software.

Dr. Rossi is a member of InSite Informing Science Institute and SBC (Brazilian Computer Society). He worked on the InSite scientific committee for reviewing papers submitted to InSite Conference'2013.

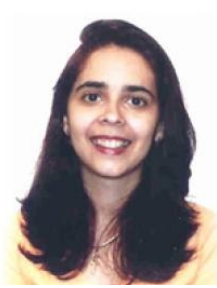

Pollyana Notargiacomo Mustaro was born in São Paulo, on October, 4, 1971. She was graduated in Pedagogy (1992) by the University of São Paulo, an institution that also earned the title of Master (1999) and Doctor of Education (2003).

She is currently a professor at Mackenzie Presbyterian University, where she develops activities for Research and Teaching at the Computer Science College and Electrical Engineering Graduate Course. Among she's areas of research, the following themes stand out: Instructional Design, Learning Objects Theory, Learning Styles, Distance Learning, Podcasts, Social Media Approaches and Technological Tools, Social Network Analysis, Hypertext Theory, Serious Games, Game Culture Studies, and Narratology.

Dr. Pollyana is a member of ACM (Association for Computing Machinery) and SBC (Brazilian Computer Society). She worked as general chair of the SBGames 2013 (SBC's conference) and on the scientific committee for reviewing papers for different conferences related to games and technology on education. 